\title{
The Survey of Correlate Causes of Learning Disabilities Prevalence among Elementary Students
}

\author{
Zeinab Mihandoost \\ Ilam Azad University, Iran \\ Tel: 60-1-7310-6894Ｅ-mail: xozns2006@yahoo.com
}

Received: February 10, $2011 \quad$ Accepted: March 8, $2011 \quad$ doi:10.5539/ass.v7n7p194

\begin{abstract}
This study aims to investigate the rate of learning disabilities prevalence and correlate causes among the elementary school students in Ilam, Iran. The research design of the current study was casual-comparative and the population of the study included the third, fourth and fifth graders of the elementary schools in Ilam, Iran. In this research, cluster sampling was employed which covered six hundred students from different classes chosen randomly from a population of clusters. The basis of this sample was the checklist approved by the school teachers on the children with learning disabilities Furthermore, the students' notebooks on the dictation, composition and mathematics were also taken into consideration. The study population was randomly divided into two groups: one was a group with learning disabilities which included 36 participants and the other was a normal group with the same size of population. Both groups were asked to answer the Wisc, Wepman and Mariyan Framstick tests as well as tests on reading, writing and math. The method of data gathering was individual information that was collected by the researcher. The result of this study revealed that $11.40 \%$ of the students in third, fourth and fifth grades of elementary schools had learning disabilities. The correlate causes of learning disabilities indicated that the students had problems with memory retention, visual acuity, and hearing memory.
\end{abstract}

Keywords: Survey, Learning disabilities, Prevalence, Elementary schools

\section{Introduction}

The field of learning disability has a relatively short history. Three phases of this history are 1) the foundation phase, 2) the transition phase, and 3) the integration phase. The foundation phase (1800-1930) occurred prior to the establishment of the field of learning disabilities. This was a period of broad scientific research on the functions and disorders of the brain. During the transition phase (1930-1960), scientific studies of the brain were applied to the clinical study of children and were then translated into ways of teaching. Psychologists and educators developed instruments for assessment and methods for teaching, and they analyzed specific types of learning disabilities. During the integration phase (1960-1980), learning disabilities became an established discipline in schools throughout the United States. The field grew rapidly as programs for learning disabilities were developed, teachers were trained, and children began to receive services (Lerner, 2006).

For many children, learning disabilities emerge when they enter school and fail to acquire academic skills. The failure often occurs in reading, but it also happens in mathematics, writing, or other school subjects. Among the behaviours frequently seen in the early elementary years are inability to attend and concentrate, poor motor skills, as evidenced in the awkward handling of a pencil and in poor writing, and difficulty in learning to read.

In the later elementary years, as the curriculum becomes more difficult, problems may emerge in other areas such as social studies or science. Emotional problems also become more of an impediment after several years of repeated failures, and students become more conscious of their poor achievement in comparison with their peers. For some students, social problems and the inability to make and keep friends increase in importance at this age level. About $40 \%$ of all children in the USA with learning disabilities are in the 6-11 age groups (U. S. Department of Education, 2002). About $60 \%$ of all children with learning disabilities are in the 12-17 age groups (U. S. Department of Education, 2002).

Before the passage of public Law 94-142 in 1975, there were only estimates of the number of the children with disabilities who were being served in schools. With this law, a nationwide count was accomplished through the individualized education program (IEP), which was written for each student in special education. This child-count information indicates that the number of students identified as having learning disabilities has increased steadily. 
The first year the law was implemented (1977- 1978), fewer than 800,000 children (or $1.8 \%$ of the enrolled school population) had received services under the category of learning disabilities in 1977 . The percentage increased to $5.8 \%$, or over 2.6 million by the 2000-2001 school years (Lerner, 2006; U. S. Department of Education, 2002).

Activities that have been done in the area of education and rehabilitation of students with learning disorders in Iran are divided into three basic periods: (1)From 1968 to 1991, the period of theoretical concepts and formation of learning disorders. (2) From 1992 to 1993, period of designing, planning, and policy making in the area of learning disorders. (3)From 1993 and after that, period of establishment of educational systems and appropriate rehabilitation for students with learning disorders and also preparing skilful staff in public and exceptional education for offering services (Bashaorlashkery, 2000).

According to American psychiatric association (DSM-IV) (2000) the learning disability is recognized when the progress report of the students is less than that excepted in standard tests of reading, mathematics and writing; it is based on age, education and intelligence level. Based on the report by the national advisory committee on the disabled children, the prevalence of learning disabilities among children is between one to three percent; while the estimate of the prevalence of learning disabilities is not the same; the amplitude of this case is reported from 1 to 30 percent in different studies (Lerner, 1999). Researches indicated that children with learning disabilities have a problem in visual and auditory perceptions (Ahadi \& Kakavand, 2003). Moreover, the findings of some research revealed that at least 33 percent of students with learning disabilities have a problem in paying due attention (Hallahan \& Kauffman, 1995; Shaywitz \& Shaywitz, 1987). In addition, the findings of some studies showed that students with learning disabilities have a problem with memory retention (Hallahan \& Kauffman, 1995).

Research Questions:

1. What percentage of students in elementary schools in Ilam, Iran, have learning disabilities problem?

2. What are the causes of learning disabilities in students at elementary level?

Research Objectives:

1. to determine the rate of learning disabilities prevalence among the students in Ilam, Iran.

2. to identify the rate of learning disabilities prevalence across the different educational levels.

3. to determine the learning method of students with learning disabilities in comparison to that in normal students.

4. to clarify the rate of low intelligence among the students with learning disabilities in comparison to that in normal students.

5. to determine the visual and auditory perceptions among the students with learning disabilities in comparison to those in normal students.

\section{Methodology}

Using the causal-comparative design, the researcher of the present study conducted the research in Ilam, Iran. The population of the study included all the students in third, fourth and fifth grades of elementary school in the school year of 2008-2009. According to the statistics of Education Office in Ilam, the elementary students made up a population of 13,986. However, for the sake of high external validity in this research, the sample size of the study included 600 students who were the third, fourth and fifth graders of elementary school. This size was chosen according to cluster sampling. Firstly, the researcher selected 4 areas randomly and then from each area 4 schools and next 3 classes in each school were selected.

The method of data collection was individual information that was conducted among the school students. In the first phase of the data collection, the information was collected from among six hundred respondents by the teachers and the researcher. After selecting the sample, the researcher referred to the classrooms and proceeded to observe the learning environment. To select the students with learning disabilities, the researcher used a non-standard test which was answered by the teachers. Then the students with learning disabilities were identified according to the quality of their composition, dictation and mathematics recorded in their notebooks. In the second phase of the survey, 12 people were randomly selected from each level of special learning disabilities: reading disability, writing disability and math disability, which came to 36 students with disability and 36 subjects were also selected from the normal group. Therefore, in this study, 72 students participated to sit for the project then, the researcher administered Wampan's hearing discrimination test, Wic memory sub-test and Marian Frastick test among the students. 


\section{Research Instruments}

In this study, based on literature review five instruments were employed for gathering the data: The Wepman's Auditory Discrimination Test: this test that is named after its initiator, measured the children's ability in comprehension and recognition of the same and different words. This test involved 30 word pairs that had a difference just in one sound and 10 word pairs that were exactly the same (Wepman, 1958). In this research, the reliability of the test was $90 \%$.

The Wechsler Memory scale: the measure of Wechsler memory (Wechsler, 1997)included 7 subscales: 1) information 2) orientation 3)mind control 4) arithmetic repeated the digits ahead 5) arithmetic repeated the digits reverse 6) total arithmetic digits and 7) visual memory. The validity and reliability of this test have been reported satisfactory in different researches. In this study, the reliability of the test was $94 \%$.

The Marian Frastick Test: this test was prepared by Marian Frastick. It could measure 5 skills of the operational perception. These 5 skills included eye dynamic harmony, text and content, scheme stability, situation in space and space relations (Naderi \& Seifnaraghi, 2003). In Hartman's (1993) study, according to the re-examination method and Cronbach' alpha coefficient, the reliability of the test was $79 \%$ and $81 \%$, respectively. In this study, the reliability of the test was $79 \%$.

The Reading, Dictation and Mathematics Tests: in this research, the reading, dictation and mathematics tests were administered for data collection. These tests were prepared by 10 teachers of third, fourth and fifth grades of the elementary school. According to Cronbach' alpha, the reliability of these tests was $78 \%, 85 \%$ and $73 \%$ in this study, respectively.

\section{Results}

In this research, the descriptive statistics was used for determining the frequency, percentage and mean of respondents. For the analysis and interpretation of the data, non-parametric chi-square and independent t-test were carried out as analytic tools. The results of this study are presented in Tables 1 - 4 .

Table 1 shows that grades and education areas, the prevalence of learning disabilities among the students in third, fourth and fifth grades of elementary school has changed from $10.48 \%$ to $12.10 \%$. Furthermore, the highest rate of prevalence was at $11.85 \%$ in Ilam city. It was $12.10 \%$ among the fifth graders; the lowest rate was $10.48 \%$ in Malekshahi city. The percentage among the third graders was $10.60 \%$; while the rate of learning disabilities prevalence for all students was $11.40 \%$.

Table 2, explains the relationship between different variables and students with learning disabilities based on $\chi^{2}$ test. There was a significant difference between the normal students and the students with learning disabilities in terms of the frequency of memory problems, trouble in doing the homework, failure history, willingness to drop out, inactivity in the class and hatred for school.

Table 3 shows the mean and standard deviation of Marian Frastick subscales for students with learning disability and students without learning disability. This table shows that the mean value for the students without learning disability was higher than the mean value for students with learning disability. This table also indicates that there is a statistically significant difference in the Marian Frastrik subscales, where eye dynamic harmony $(t=-5.2), \rho=.000$, text and content $(t=-3.85), \rho=.000$, figure stability $(-6.85), \rho=.000$, situation in space $(t=-4.94), \rho=.000$, space relationship $(\mathrm{t}=-4.96), \rho=.000$ and total marks $(\mathrm{t}=-7.57), \rho=.000$.

Table 4 shows the mean and standard deviation of Wechsler (Wisc) subscales for students with learning disability and students without learning disability. This table shows that the mean value for students without learning disability was higher than the mean value for students with learning disability. This table also shows that there is statistically significant difference in the Wisc subscales, where personal and general information $(t=-6.57), \rho=.000$, finding the ways (-6.65), $\rho=.000$, intellectual control $(\mathrm{t}=-6.82), \rho=.000$, repeated the digits ahead $(\mathrm{t}=-6.77), \rho=.000$, repeated the digits reverse $(\mathrm{t}=-5.86), \rho=.000$, visual memory $(\mathrm{t}=1.69), \rho=.000$ and total mark for digits $(\mathrm{t}=.85)$, $\rho=.000$.

\section{Discussion}

In this survey, the following research objectives were investigated:

Objective 1: To determine the rate of learning disabilities prevalence across the different educational levels. The results of this research indicated that the rate of learning disabilities has been $11.40 \%$. In the final report, the rate of prevalence was $4.29 \%$ of whole population, but the rate of this case changed from $1 \%$ to $30 \%$ (Lerner, 2006). The cause of differences in the rate of prevalence was related to some reasons such as lack of an appropriate and precise 
instrument to measure the learning disabilities or the heredity and genetic reasons that caused the rate of prevalence of the learning disabilities in some areas to be more than in other regions.

Objective 2: To determine the rate of learning disabilities prevalence across the different educational levels. In this research, based on the second objective it became known that there were significant differences in the rate of learning disabilities prevalence across different educational levels and this difference was higher in the fifth grade rather than in other grades; the fifth graders showed $12.10 \%$ of learning disabilities problems.

Objective 3: To determine the learning method of students with learning disabilities in comparison to that in normal students. According to the third objective of current study, it was demonstrated that students with learning disabilities used visual and auditory methods less than the normal students.

Objective 4: to clarify the rate of low intelligence among the students with learning disabilities in comparison to that in normal students. The results of this study explained that students with learning disabilities got a mark higher than average in inattention sub-tests in comparison to the normal students and this difference was significant, as well.

Objective 5: to determine the visual and auditory perceptions among the students with learning disabilities in comparison to those in normal students. The finding of this survey revealed that the mistake of the students with learning disabilities was higher than those of the normal students in Wepman's audition test. Likewise, there were significant differences in finding the shape in background sub-tests of Marian Frastick test, and this difference was lower for the students with learning disabilities rather than in the normal group. Furthermore, the students with learning disabilities were weak in visual and hearing memory; the mean of the students with learning disabilities was 5.85 in Wisc visual memory test, while the mean for the normal student was 8.77 in the same test. In addition, the mean of the mark of the students with learning disabilities was lower than that in normal children in repeating digits ahead, repeating digits reverse and even whole digits that illustrated the numeric memory of the students. This finding is supported by Allahyari (1992), and Torgeson (1997)The teachers generally evaluated the students with learning disabilities as inactive and unsuccessful in doing the class work. This is the most important reason for their dropouts.

\section{References}

Ahadi, H., \& Kakavand, R. (2003). Learning disorder. Tehran: Arasbaran.

Allahyari. (1992). Study and compare some of the traits of ordinary and dyslexia students. M.S, University of Iran, Tehran.

American Psychiatric Association. (2000). Diagnostic and ststistical manual of mental disorders (Vol. 4). Washington, DC: American Psychiatric Association.

Bashaorlashkery, M. (2000). Learning Failures. Tehran: Honar.

Hallahan, D. P., \& Kauffman, J. M. (1995). Toward a culture of disability. In J. M. Kauffman \& D. P. Hallahan (Eds.), The illusion of full inclusion: A comprehensive critique of a current educational: Bandwaa.

Hartman, C. (1993). Transition to higher education. In S. Kroeger \& J. Schuck (Eds.), New directions for student services. Responding to disability issues in student affairs. San Francisco: Jossey-Bass.

Lerner, J. (1999). Learning disabilities (Vol. 8). Bosto, MA: Hougton Mifflin.

Lerner, J. (2006). Learning disability and related disorder, characteristic and teaching strategy. Boston: Houghton Mifflin.

Naderi, E., \& Seifnaraghi, M. (2003). Specific learning disabilities: Stages of diagnosis and rehabilitational methods. Tehran: Mikyal.

Shaywitz, S. E., \& Shaywitz, B. A. (1987). Attention deficit disorder: current perspectives. Pediatr Neurol, 3, 129-135.

Torgesen, J. (1997). The prevention and remediation of reading difficulties: Evaluating what we know from research. Journal of Academic Language Therapy, 1, 11-47.

U. S. Department of Education. (2002). Guidance for the Reading First Program, [Online] Avaible: http://www.ed.gov/programs/readingfirst/guidance.doc.

Wechsler, D. (1997). Wechsler memory scale-Third edition. San Antonio, TX: Psychological Corp.

Wepman, M. (1958). (Vol. 3). Chicago: Language Research Associates. 
Table 1 . The percentage of the students with learning disability based on grade and city, in Ilam, Iran

\begin{tabular}{llll}
\hline Grade & Percent & City & Percent \\
\hline Third & 10.60 & Ilam & 11.85 \\
Fourth & 11.50 & Ivan & 11.56 \\
Fifth & 12.10 & Mehran & 11.58 \\
Total & 11.40 & Malekshahi & 10.48
\end{tabular}

Table 2. Chi-square for different variables in students with learning disabilities

\begin{tabular}{lll}
\hline Variables & $\chi^{2}$ & $\rho$ \\
\hline Difficulty in remembering & 36.2 & .000 \\
Thought organization & 24.5 & .000 \\
The normal student appearance & 3.8 & .05 \\
Difficulty in doing assignment & 38.2 & .000 \\
The normal student game & 4.9 & .01 \\
Reprobate background & 20.1 & .000 \\
Revival background & 39.2 & .000 \\
Willing into leaving study & 4.1 & .05 \\
Hate of school & 39.4 & .000 \\
Inactivity in classroom & 51.1 & .000 \\
\hline
\end{tabular}

Table 3. t-test and the mean compare LD and Non-LD students based on the Marian Frastrik

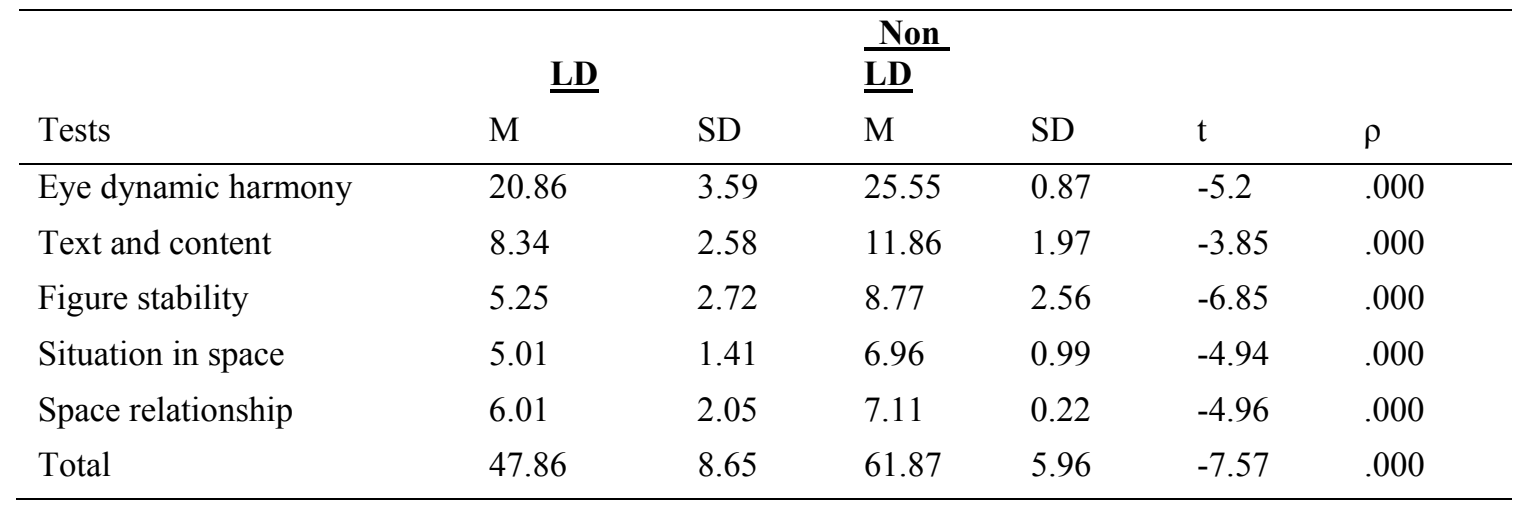

Table 4. t-test and the mean comparison of LD and non-LD based Wechsler scale

\begin{tabular}{lllllll}
\hline Sub-Tests Wisc & $\underline{\mathbf{L D}}$ & \multicolumn{2}{c}{$\underline{\underline{\text { Non-LD }}}$} & \multicolumn{2}{l}{} \\
\hline Information & $\mathrm{M}$ & $\mathrm{SD}$ & $\mathrm{M}$ & $\mathrm{SD}$ & $\mathrm{t}$ & $\rho$ \\
Orientation & 0.98 & 0.23 & 2.86 & 0.95 & -6.57 & .000 \\
Mind control & 1.56 & 0.98 & 3.57 & 0.87 & -6.65 & .000 \\
Arithmetic repeated the digits ahead & 0.99 & 0.45 & 3.95 & 1.66 & -6.82 & .000 \\
Arithmetic repeated the digits reverse & 3.86 & 0.59 & 4.56 & 0.95 & -6.77 & .000 \\
Total Arithmetic digits & 2.85 & 0.45 & 3.72 & 0.79 & -5.86 & .000 \\
Visual memory & 6.85 & .88 & 8.75 & .85 & -6.98 & .000 \\
\hline
\end{tabular}

